\title{
Resistência de seis cultivares de soja ao Colletotrichum truncatum (Schwein) em dois estádios fenológicos
}

\author{
Resistance of six soybean cultivars to Colletotrichum truncatum (Schwein) in two phenologic stages
}

\author{
Ivan Francisco Dressler da Costa ${ }^{1}$ Ricardo Silveiro Balardin ${ }^{2}$ Luis Aquiles Medeiros $^{3}$ \\ Tânia Maria Bayer ${ }^{4}$
}

\section{RESUMO}

Experimentos para a avaliação de resistência de soja a antracnose foram instalados na Universidade Federal de Santa Maria. Seis cultivares foram selecionadas quanto a sua reação à inoculação com o patógeno (duas resistentes, duas intermediárias e duas suscetíveis) e inoculadas com isolados de Colletotrichum truncatum (Schwein) nos estádios $V_{1} / V_{2}$ e $V_{5} / V_{6}$. Estas reações foram determinadas a partir de uma escala de severidade de sintomas, que variou de zero a nove, e que foi utilizada para determinar os índices de virulência dos isolados e de resistência das cultivares. Os resultados de inoculação nos estádios $V_{1} / V_{2}$ mostraram diferenças quanto à reação das cultivares inoculadas, quando comparadas às inoculações realizadas no estádio $V_{5} / V_{6}$. O aumento de resistência no estádio mais avançado sugere o efeito de "resistência de planta adulta".

Palavras-chave: Antracnose, Glycine max, planta adulta.

\section{ABSTRACT}

Experiments for the evaluation of soybean resistance to anthracnose were carried out at Federal University of Santa Maria. Six cultivars were selected based on their reaction to the pathogen inoculation (two resistant, two intermediate and two susceptible), and submitted for inoculation in stadiums $V_{1} / V_{2}$ and $V_{5} / V_{6}$. Plant reactions were determined from symptom severity scale (zero to nine), and used to determine the virulence and resistance indexes. The results of inoculation in stages $V_{1} / V_{2}$ showed differences in the reaction of cultivars when compared to the inoculations carried out in stage $V_{5} / V_{6}$. High resistance in $v 5 / v 6$ suggests a mechanism of "resistance of adult plant".

Key words: Anthracnose, Glycine max, adult plant.

\section{INTRODUÇÃO}

Embora a antracnose da soja, causada pelo fungo $\boldsymbol{C}$. truncatum, seja considerada como uma das principais doenças na Região do Cerrado brasileiro, principalmente sob condições de alta umidade, podendo causar a perda total da lavoura (EMBRAPA, 2003), poucos trabalhos têm sido realizados para determinar a resistência de cultivares de soja. Mesmo a recomendação oficial de controle não trata do uso de cultivares resistentes, preferindo métodos culturais, como a rotação de culturas, manejo do solo e adubação potássica balanceada, maiores espaçamentos e menor densidade de plantas, visando a diminuir a pressão de inóculo (RECOMENDAÇÕES, 2004; BALARDIN, 2002; BORKERT et al., 1994).

Um dos métodos de controle de fitopatógenos com melhores resultados, a resistência genética tem sido largamente utilizada como estratégia, em diversas culturas; porém, para que esta estratégia funcione a contento, é necessário que exista um conhecimento dos genes que estão envolvidos (BRAMMER et al., 2004). A resistência genética tem sido investigada em diversos patossitemas.

Em trigo, dois tipos de resistência a patógenos foram investigados. A chamada "resistência raça-específica", a qual obedece ao fundamento expresso pela lei do gene-a-gene, com pareamento

\footnotetext{
'Departamento de Defesa Fitossanitária, Universidade Federal de Santa Maria (UFSM), Clínica Fitossanitária, Campus Universitário, 97105-900, Santa Maria, RS, Brasil. Email: idresler@smail.ufsm.br. Autor para correspondência.

${ }^{2}$ Departamento de Defesa Fitossanitária, UFSM, Santa Maria, RS, Brasil.

${ }^{3}$ Escola Agrotécnica Federal de Rio do Sul, Rio do Sul, SC, Brasil.

${ }^{4}$ Curso de Agronomia, Clínica Fitossanitária, UFSM, Santa Maria, RS, Brasil.
} 
específico entre genes do patógeno e do hospedeiro, é qualitativamente expressa durante todo o ciclo das plantas (LIU et al., 2001). Outro tipo de resistência é a chamada "resistência parcial", que atua retardando a infecção, crescimento e reprodução do patógeno em plantas adultas, mas não em plântulas (SHANER, 1973; HAUTEA et al., 1987). A durabilidade da resistência é relacionada à expressão de um conjunto de genes menores e cuja herança é considerada complexa. Algumas cultivares de trigo que apresentam maior resistência durável à ferrugem da folha são também as que têm resistência de planta adulta (BARCELLOS et al., 2000; ROELF, 1988).

A soja pode apresentar diferenças de suscetibilidade à infeccão por $\boldsymbol{C}$. truncatum em vários de seus órgãos, como nas folhas (KHARE \& CHACKO, 1983), em sementes (HAPPERLY et al., 1983; KHARE $\&$ CHACKO, 1983), nas vagens e ramos (BACKMAN et al., 1982). Testes de determinação de resistência contra C. truncatum em variedades de soja, sob condicões epifitóticas, na região de Nagpur, Índia, demonstraram que as variedades "JS-22" e "PKV-1" são altamente resistentes ao patógeno, enquanto que a variedade "MACS-13" se mostrou apenas resistente (GHAWDE et al., 1996). Com a inoculação de diferentes raças de $\boldsymbol{C}$. lindemuthianum em diferentes cultivares de feijoeiro, foi observado o desenvolvimento de sintomas mais severos nos estádios iniciais de desenvolvimento da planta, demonstrando que a idade da planta influencia a severidade dos sintomas (MEDEIROS, 2004).

Quando plantas de soja foram inoculadas com Microsphaera diffusa, no estádio V , mostraramse mais suscetíveis à infecção do que aquelas inoculadas no estádio $\mathrm{V}_{3}$. Algum tempo após a inoculação, ocorreu redução dos sintomas em todos os tipos de folhas, mostrando melhor desenvolvimento do patógeno em plantas jovens (MIGNUCCI \& LIM, 1980). A resistência parcial foi identificada em algumas cultivares de soja inoculadas com Sclerotinia sclerotiorum, e com expressão consistente em vários testes de campo (HOFFMAN, 2002). Apesar da identificação de fontes de resistência em cultivares comerciais, estas são em número limitado, não prevenindo completamente as perdas de rendimento devidas à doença (YANG et al., 1999). Testes indicaram que a resistência parcial em soja contra $S$. sclerotiorum é influenciada por fatores do ambiente (PENNYPACKER \& RISIUS, 1999; HOFFMAN et al., 2004).

O objetivo deste trabalho foi determinar a reação de cultivares de soja, indicadas para diferentes regiões do Brasil, à infecção por isolados de $\boldsymbol{C}$. truncatum e a expressão de resistência ao patógeno, quando inoculadas nos estádios fenológicos $\mathrm{V}_{1} / \mathrm{V}_{2} \mathrm{e}$ $\mathrm{V}_{5} / \mathrm{V}_{6}$.

\section{MATERIAL E MÉTODOS}

Este trabalho foi conduzido em casa de vegetação e em laboratório, na Clínica Fitossanitária do Departamento de Defesa Fitossanitária, CCR/UFSM, Santa Maria, RS, no período de março de 2003 a janeiro de 2004.

As cultivares de soja, inoculadas com os isolados do fungo $\boldsymbol{C}$. truncatum, foram obtidas do conjunto de cultivares comerciais indicadas para semeadura nas diversas regiões produtoras de soja no Brasil. No presente experimento, foram testadas seis cultivares, duas resistentes, duas intermediárias e duas suscetíveis à antracnose, selecionadas a partir de ensaios preliminares, nos quais foram realizadas inoculações com $\boldsymbol{C}$. truncatum na fase juvenil $\left(\mathrm{V}_{1} / \mathrm{V}_{2}\right)$ sobre 49 cultivares de soja (COSTA, 2005). As cultivares utilizadas neste experimento foram "Anta 82" e "MSoy 8400" (resistentes), "BRS 154" e "CD 205" (intermediárias) e "Emgopa 316" e "Tabarana" (suscetíveis). Três isolados de $\boldsymbol{C}$. truncatum foram obtidos a partir de plantas infectadas, coletadas em campo nos municípios de Itaara, Júlio de Castilhos e São Pedro do Sul (ITA, JCa e SPe), e o quarto isolado (Pel1) proveio da Micoteca da Faculdade de Agronomia Eliseu Maciel, UFPel, Pelotas, RS.

$\mathrm{O}$ fungo foi cultivado em meio BDA e, quando as colônias mostraram-se com crescimento micelial com diâmetro ao redor de $2 \mathrm{~cm}$, foi repicado para meio de cultura de Mathur (MATHUR et al., 1950), para induzir a esporulação. O período de incubação de cada isolado foi de 14 dias, em condições de fotoperíodo $12 / 12 \mathrm{~h}$ (luz/escuro) e temperatura de $21^{\circ} \mathrm{C}$, respectivamente. Culturas puras foram obtidas a partir de culturas monospóricas, sendo geneticamente similares, sem interferência de variabilidade genética intra-isolado.

A multiplicação do patógeno foi realizada em meio Mathur modificado, onde, sobre o meio ainda líquido, foram acrescentados pedaços de $2 \mathrm{~cm}$ de folhas de taboa (Tipha sp.) previamente autoclavadas, sobre as quais foi inoculado cada isolado. Após sete dias em crescimento nas mesmas condições descritas anteriormente, pedaços deste meio de cultura, com abundante crescimento de acérvulos, foram transferidos para frascos com tampa de rosca, com capacidade para $100 \mathrm{~mL}$, contendo folhas de taboa autoclavadas, onde foi produzido o inóculo necessário para inoculação nas diferentes cultivares de soja. Após 
15 dias de crescimento, quando as folhas de taboa se apresentaram totalmente colonizadas pelo fungo, foi acrescentada nos frascos de vidro uma mistura de água mais o espalhante TWEEN 80, na concentração de $0,5 \%$ (0,5mL de Tween 80 + água destilada esterilizada QSP $100 \mathrm{~mL}$ ), para facilitar a liberação dos esporos. A mistura foi agitada vigorosamente, para retirada dos esporos, e, em seguida, foi filtrada para retirada de impurezas. No líquido resultante (suspensão de esporos), foi realizado um ajuste, com auxílio de uma Câmara de Neubauer, para alcançar a concentração final de 1,2 x $10^{6}$ esporos $\mathrm{mL}^{-1}$.

As inoculações foram realizadas com o auxílio de um micropulverizador, quando as plantas apresentaram as duas primeiras folhas primárias completamente expandidas e primeiro trifólio aberto $\left(\mathrm{V}_{1}\right)$ $\mathrm{V}_{2}$ ) e por ocasião da emissão do quinto e do sexto nós (sexto e sétimo trifólios abertos) $\left(\mathrm{V}_{5} / \mathrm{V}_{6}\right)$. Para o estádio $\mathrm{V}_{1} / \mathrm{V}_{2}$, as cultivares de soja foram semeadas em bandejas plásticas, com quatro cultivares/bandeja e 10 plantas/ cultivar. Para o estádio $\mathrm{V}_{5} / \mathrm{V}_{6}$ foram utilizados vasos plásticos, com cinco plantas/vaso e dois vasos/ tratamento, num total de 24 tratamentos (seis cultivares e quatro isolados) e 10 repetições/tratamento (uma planta/repetição). As plantas foram mantidas, após as inoculações, em casa de vegetação de ambiente parcialmente controlado $\left(25^{\circ} \mathrm{C} ; 80 \%\right.$ UR $)$, e as avaliações foram realizadas 20 dias após a inoculação, em ambos os casos. A severidade dos sintomas foi obtida pela avaliação das lesões nas folhas, determinando-se os graus de resistência das plantas e de virulência dos isolados testados através de uma escala de notas de severidade, com as seguintes atribuições: 0 (sem sintomas); 0,1-1,0 (lesões < 1mm no pecíolo e/ou nervuras); 1,1-2,0 (poucas lesões $<3 \mathrm{~mm}$ limitadas ao pecíolo); 2,1-3,0 (poucas lesões $<3 \mathrm{~mm}$ limitadas às nervuras); 3,1-4,0 (numerosas lesões < 3mm limitadas às nervuras e/ou pecíolos); 4,1-5,0 (lesões no pecíolo e/ou nervuras > 3mm e $<5 \mathrm{~mm}$ ); 5,1-6,0 (lesões no pecíolo e/ou nervuras $>5 \mathrm{~mm}$ e $<10 \mathrm{~mm}$ ); 6,1-7,0 (lesões $>10 \mathrm{~mm}$ no pecíolo e/ou nervuras); 7,1-8,0 (lesões > $10 \mathrm{~mm}$ no pecíolo e/ou nervuras, com esporulação) e 8,1-9,0 (folhas mortas).

Para o cálculo do Índice de Virulência (IV), foi utilizada a equação "IV = reações suscetíveis/total de cultivares inoculadas" e para o Índice de Resistência (IR) $\mathrm{IR}=$ reações suscetíveis/total de patótipos inoculados.

A análise da variância dos dados de severidade foi realizada para determinar a significância da variação entre as cultivares de soja e as médias comparadas pelo Teste de Scott-Knott $(\mathrm{P}=0,05)$.

\section{RESULTADOS E DISCUSSÃO}

Para a reação genética de cultivares de soja, em função da inoculação no estádio $\mathrm{V}_{5} / \mathrm{V}_{6}$, a análise da variância mostrou diferenças significativas entre as cultivares, em função de cada isolado inoculado, mas, quando se levou em consideração os diferentes isolados inoculados em cada cultivar, não houve diferença significativa, ao nível de 5\% de probabilidade (Tabela 1). Estes resultados indicam que as cultivares apresentaram diferentes graus de reação à infecção de cada isolado do fungo, sendo a reação resistente maior naquelas cultivares que apresentaram resistência juvenil; porém, todo o conjunto de cultivares apresentou reação resistente ou intermediária, de acordo com a escala de avaliação. De uma maneira geral, os resultados mostraram que as cultivares inoculadas em estádios fenológicos mais avançados apresentaram um índice de resistência maior, não dependendo da

Tabela 1 - Severidade média de antracnose causada por quatro isolados de Colletotrichum truncatum, reação genética, índice de resistência (IR\%) e índice de virulência (IV\%) de seis cultivares de soja inoculadas no estádio $V_{5} / V_{6}$.

\begin{tabular}{|c|c|c|c|c|c|c|c|c|c|}
\hline \multirow{2}{*}{ Cultivares } & \multicolumn{9}{|c|}{ Isolados de $C$. truncatum } \\
\hline & Pel1 ${ }^{1}$ & $\mathrm{RG}^{2}$ & ITA $^{1}$ & $\mathrm{RG}^{2}$ & $\mathrm{SPe}^{1}$ & $\mathrm{RG}^{2}$ & $\mathrm{JCa}^{1}$ & $\mathrm{RG}^{2}$ & IR \\
\hline Tabarana & $4,0 a^{4}$ & I & $3,0 \mathrm{a}$ & $\mathrm{R}$ & $3,0 \mathrm{a}$ & $\mathrm{R}$ & $3,5 a$ & I & 50 \\
\hline Emgopa 316 & $2,9 \mathrm{a}$ & $\mathrm{R}$ & $2,3 \mathrm{a}$ & $\mathrm{R}$ & $2,0 \mathrm{a}$ & $\mathrm{R}$ & $1,9 \mathrm{~b}$ & $\mathrm{R}$ & 100 \\
\hline CD 205 & $0,6 b$ & $\mathrm{R}$ & $0,8 b$ & $\mathrm{R}$ & $0,5 b$ & $\mathrm{R}$ & $0,7 \mathrm{c}$ & $\mathrm{R}$ & 100 \\
\hline BRS 154 & $1,3 b$ & $\mathrm{R}$ & $1,5 b$ & $\mathrm{R}$ & $1,3 b$ & $\mathrm{R}$ & $1,7 \mathrm{~b}$ & $\mathrm{R}$ & 100 \\
\hline Anta & $0,3 b$ & $\mathrm{R}$ & $0,6 \mathrm{~b}$ & $\mathrm{R}$ & $1,0 \mathrm{~b}$ & $\mathrm{R}$ & $0,9 \mathrm{c}$ & $\mathrm{R}$ & 100 \\
\hline MSoy 8400 & $0,6 b$ & $\mathrm{R}$ & $0,5 b$ & $\mathrm{R}$ & $0,6 b$ & $\mathrm{R}$ & $0,5 \mathrm{c}$ & $\mathrm{R}$ & 100 \\
\hline IV $(\%)$ & & 16 & & 0 & & 0 & & 16 & \\
\hline
\end{tabular}

${ }^{1}$ Pel1: Pelotas; ITA: Itaara; SPe: São Pedro do Sul; JCa: Júlio de Castilhos;

${ }^{2}$ Reação genética: $\mathrm{I}$ = intermediário; $\mathrm{R}$ = resistente;

${ }^{3}$ Médias seguidas da mesma letra na vertical não diferem entre si pelo teste Scott-Knott ao nível de $5 \%$.

Ciência Rural, v.36, n.6, nov-dez, 2006. 
condição da reação genética, quando inoculadas no estádio de plântula. Estes resultados concordam com MIGNUCCI \& LIM (1980), que, em trabalho realizado com soja, demonstraram a resistência de planta adulta à infecção por M. diffusa, bem como com o trabalho de MEDEIROS (2004), avaliando a resistência de cultivares de feijoeiro submetidos à inoculação por diferentes raças de $\boldsymbol{C}$. lindemuthianum.

Para o isolado Pel1, em função das cultivares testadas, houve diferença estatística entre "Tabarana" e "Emgopa 316", em relação às outras cultivares e, embora na reação de plântula estas duas cultivares tenham se mostrado com alta suscetibilidade a este isolado (Tabela 2), no estádio $\mathrm{V}_{5} / \mathrm{V}_{6}$ "Tabarana" teve reação intermediária e "Emgopa 316" se mostrou resistente. Para os isolados ITA e SPe, embora a análise da variância tenha mostrado diferença entre as cultivares, estas se mostraram todas com reação resistente. $\mathrm{O}$ isolado $\mathrm{JCa}$, em relação às cultivares testadas, embora tenha mostrado diferença estatística, agrupando-as em três grupos distintos: "CD 205", “Anta 82" e "MSOY 8400"; "Emgopa 316" e "BRS 154" e "Tabarana", apresentou diferença apenas para "Tabarana”, com reação intermediária (Tabela 1).

Quando se analisou as cultivares em função dos isolados, não foram observadas diferenças entre estes, mostrando que houve certa estabilidade entre os isolados para causar doença nas plantas de soja, independentemente da cultivar analisada. Embora a reação da cultivar "Tabarana" tenha apresentado índice de resistência de 50\%, estatisticamente não ocorreram diferenças significativas entre os isolados testados (Tabela 1).

Houve diferença entre as médias de severidade das seis cultivares inoculadas com o isolado

Tabela 2 - Médias de severidade da antracnose e de resistência em seis cultivares de soja inoculadas, nos estádios $V_{1} / V_{2}$ e $\mathrm{V}_{5} / \mathrm{V}_{6}$, pelo isolado Pell de Colletotrichum truncatum.

\begin{tabular}{lcccc}
\hline & \multicolumn{4}{c}{ Estádio fenológico/Reação } \\
\hline Cultivares & $\mathrm{V}_{1} / \mathrm{V}_{2}{ }^{1}$ & Reação $^{2}$ & $\mathrm{~V}_{5} / \mathrm{V}_{6}{ }^{1}$ & Reação $^{2}$ \\
Tabarana & 7,7 & $\mathrm{~S}$ & 4,0 & $\mathrm{I}$ \\
Emgopa 316 & 6,2 & $\mathrm{~S}$ & 2,9 & $\mathrm{R}$ \\
CD 205 & 5,9 & $\mathrm{I}$ & 0,6 & $\mathrm{R}$ \\
BRS 154 & 3,5 & $\mathrm{I}$ & 1,3 & $\mathrm{R}$ \\
Anta 82 & 1,4 & $\mathrm{R}$ & 0,3 & $\mathrm{R}$ \\
MSOY 8400 & 2,8 & $\mathrm{R}$ & 0,6 & $\mathrm{R}$ \\
\hline
\end{tabular}

${ }^{1} \mathrm{~V}_{1} / \mathrm{V}_{2}$ : primeiro e segundo nós; $\mathrm{V}_{5} / \mathrm{V}_{6}$ : quinto e sexto nós (Fehr \& Caviness, 1977);

${ }^{2} \mathrm{~S}$ : suscetível; I: intermediário; R: resistente.
Pell, nos estádios fenológicos $\mathrm{V}_{1} / \mathrm{V}_{2} \mathrm{e}_{5} / \mathrm{V}_{6}$ (Tabela 2). Pode-se observar que, para todas as cultivares, a reação de resistência se mostrou mais acentuada quando $C$. truncatum foi inoculado no estádio $\mathrm{V}_{5} / \mathrm{V}_{6}$, sugerindo efeitos de resistência de planta adulta. A reação de resistência foi maior para aquelas cultivares que já apresentavam certo grau de resistência em $\mathrm{V}_{1} /$ $\mathrm{V}_{2}$, como “Anta 82” e "MSOY 8400”, e, mesmo para aquelas com reação suscetível no estádio de plântula ("Tabarana" e "Emgopa 316"), a resistência foi maior. MEDEIROS (2004) demonstrou que, quando ocorre um aumento de resistência de um estádio de fenológico para outro, seja da condição suscetível para resistente ou de suscetível para intermediário, também ocorre uma diminuição no número de lesões, sendo que estas se mostram maiores em plantas jovens, submetidas a inoculações, do que em plantas adultas.

\section{CONCLUSÕES}

De acordo com as variações ocorridas entre as reações obtidas com as inoculações, realizadas em dois estádios vegetativos $\left(\mathrm{V}_{1} / \mathrm{V}_{2}-\mathrm{V}_{5} / \mathrm{V}_{6}\right)$ da soja, podese concluir que ocorre um aumento de resistência das plantas, conforme ocorre o avanço no seu ciclo de desenvolvimento, sendo que plantas em estado juvenil se mostram mais propícias ao desenvolvimento de relações com o patógeno, sugerindo que as cultivares podem diferir geneticamente quanto à resistência ao fungo C. truncatum. Neste sentido, aqueles com maior resistência poderiam ser utilizados em locais onde o fungo é limitante à produção de soja, permitindo sua utilização em programas de controle integrado de doenças de final de ciclo.

\section{REFERÊNCIAS}

BACKMAN, P.A. et al. Yield losses in soybeans from anthracnose caused by Colletotrichum truncatum. Plant Disease, v.66, n.11, p.1032-1034, 1982.

BALARDIN, R.S. Doenças da soja. Santa Maria: UFSM, 2002. $107 p$

BARCELLOS, A.L. et al. Inheritance of adult plant leaf rust resistance in the Brazilian wheat cultivar Toropi. Plant Disease, v.84, n.1, p.90-93, 2000.

BORKERT, C.V. et al. Seja o doutor da sua soja. Arquivo do Agrônomo, n.5. Potafós, 1994. 6p. (Informações Agronômicas, n.66).

BRAMMER, S.P. et al. Mapeamento de genes de resistência à ferrugem da folha em cultivares de trigo (Triticum aestivum L. Thell). Acesso em: 14 dez. 2004. Online. Disponível em: http://www.redbio.org/portal/encuentros/ enc_2001/simposios/S-10/S.P.Brammer.pdf. 
COSTA, I.F.D. Controle de doenças de final de ciclo na cultura da soja. 2005. Tese (Doutorado em Produção Vegetal) - Curso de Pós-graduação em Agronomia, Universidade Federal de Santa Maria, Santa Maria. 101p.

EMBRAPA. Tecnologias de produção de soja região central do Brasil. Londrina: EMBRAPA Soja, 2003. 32p. (Sistema de Produção n.1).

FEHR, W.R.; CAVINESS, C.E. Stage of soybean development. Ames: Iowa State University, 1977. 12p. (Special Report, 80).

GHAWDE, R.S. et al. Evaluation of fungicides and screening of varieties against pod blight of soybean caused by Colletotrichum truncatum (Schw.). Andus and Moore. Journal of Soil and Crops, v.6, n.1, p.97-99, 1996.

HAUTEA, R.A. et al. Inheritance of partial resistance to powdery mildew in spring wheat. Theor Appl Genet, v.73, p.609-615, 1987.

HAPPERLY, P.R. et al. Soybean anthracnose and its seed assay in Puerto Rico. Seed Science and Technology, v.11, n.2, p.371-380, 1983 .

HOFFMANN, L.L. Controle de oídio e doenças de final de ciclo em soja. 2002. 185f. Dissertação (Mestrado em Agronomia) - Curso de Pós-graduação em Agronomia, Universidade de Passo Fundo.

HOFFMANN, L.L. et al. Efeitos da rotação de cultura, de cultivares e da aplicação de fungicida sobre o rendimento de grãos e doenças foliares em soja. Fitopatologia Brasileira, v.29, p.245-251, 2004.

KHARE, M.N.; CHACKO, S. Factors affecting seed infection and transmission of Colletotrichum dematium f. sp. truncata in soybean. Seed Science and Technology, v.11, p.853858,1983 .

LIU, S. X. et al. Identification of molecular markers associated with adult plant resistance to powdery mildew in common wheat cv. Massey. Crop Science, v.41, p.1268-1275, 2001.

MATHUR, R.S. et al. Sporulation of Colletotrichum lindemuthianum in culture. Phytopathology, v.40, p.104$11,1950$.

MEDEIROS, L.A.M. Resistência genética do feijão (Phaseolus vulgaris L.) ao Colletotrichum lindemuthianum. 2004. 116p. Tese (Doutorado em Produção Vegetal) - Curso de Pós-graduação em Agronomia, Universidade Federal de Santa Maria, Santa Maria.

MIGNUCCI, J.S.; LIM, S.M. Powdery mildew (Microsphaera diffusa) development on soybeans with adult-plant resistance. Phytopathology, v.70, n.9, p.919-921, 1980.

PENNYPACKER, B.W.; RISIUS, M.L. Environmental sensitivity of soybean cultivars response to Sclerotinia sclerotiorum. Phytopathology, v.89, p.618-622, 1999.

RECOMENDAÇÕES TÉCNICAS. REUNIÃO DE PESQUISA DE SOJA DA REGIÃO CENTRAL DO BRASIL, 26, 2004, Ribeirão Preto. Documentos... Londrina, PR: Embrapa Soja, 2004. v. 234

ROELF, A.P. Resistance to leaf and stem rust in wheat. In: SIMMONDS, N.W.; RAJARAM, S. Breeding strategies for resistence to the rust of wheat. México: CIMMYT, 1988. p.10-22.

SHANER, G. Evaluation of slow-mildewing resistance of knox wheat in the field. Phytopathology, v.63, p.609-615, 1973.

YANG, X.B. et al. Soybean varietal response and Yield loss caused by Sclerotinia sclerotiorum. Plant Disease, v.83, p.456$461,1999$. 